\title{
Respiratory motion and its compensation possibilities in the modern external beam radiotherapy of lung cancer
}

\author{
Marta Adamczyk ${ }^{1}$, Tomasz Piotrowski ${ }^{1,2}$
}

The aim of this paper is to present a systematic review of the current characteristics and recent development of commercially available respiratory motion solutions and their compensation possibilities in the external beam radiotherapy treatment of lung cancer. The most commonly used X-ray and radiotherapeutic technologies are presented, as well as their division into pre-treatment methods and intra-treatment verification. The article discusses the most important technological achievements that allow radiation to be safely applied in the lung region and reports the potential advantages and limitations of each. Finally, it presents details concerning selected research trends and problems related to motion compensation.

NOWOTWORY J Oncol 2017; 67, 5: 292-296

Key words: external beam radiation therapy, lung cancer, respiratory motion

\section{Introduction}

Computed tomography $(\mathrm{CT})$ is the basic imaging method for the planning of radiation dose distribution in external beam radiation therapy [1]. Based on the images obtained during a CT scan, it is possible to determine the geometric parameters of therapeutic beams so as to deposit the dose precisely in the tumor volume and reduce its value in healthy tissues [1]. However, a single three-dimensional reconstruction of tomographic images is usually done before the course of radiotherapy. Therefore, during the whole external beam radiation therapy treatment, it is necessary to:

- use dedicated anatomical fixation accessories;

- use filling procedures dedicated for the organs within the irradiated area;

- compensate anatomical changes by applying appropriate therapeutic margins to define irradiated volumes;

- perform pre-fraction verification procedures to check the patient's geometry before each daily irradiation as well as inspect the patient's position during external beam treatment (intra-fraction verification) [2-6].
In case of tumors significantly affected by respiratory motion (e.g. lung cancer), the radiotherapeutic procedures mentioned above do not guarantee the effective and precise delivery of the planned dose. Therefore, in the last few decades, physicists and engineers working on upgrades for CT scanners and therapeutic devices used in external beam therapy have focused on introducing and optimizing the possibility of compensating respiratory motion during the treatment of lung cancer patients [7].

The aim of this paper is to present the most common commercially available diagnostic and therapeutic imaging technologies used for the compensation of respiratory motion during external beam radiation therapy treatment for lung cancer. The article reports the most important technological achievements that allow radiation to be safely applied in the lung region, as well as the potential advantages and limitations of each solution.

\section{Respiratory motion compensation methods}

Respiratory motion compensation methods can be divided into two groups:

\footnotetext{
${ }^{1}$ Department of Medical Physics, Greater Poland Cancer Center in Poznań, Poland

${ }^{2}$ Department of Electroradiology, Faculty of Health Sciences, Poznań University of Medical Sciences, Poland
} 
1. Methods based on CT imaging performed before the course of external beam radiation therapy.

2. Compensation procedures performed on a therapeutic device during the course of radiotherapy.

\section{CT-based compensation}

A single $\mathrm{CT}$ lung imaging procedure does not allow to reliably estimate the size, position and respiratory motion of the tumor due to the inadequate quality of the obtained images, degraded by the appearance of artefacts that affect the size, shape and density of scanned anatomical structures (including the tumor). For diagnostic purposes, this problem is eliminated by breath-hold scanning techniques. Unfortunately, during external beam treatment, the time required to provide a daily therapeutic dose, along with the patient's reduced lung capacity, eliminates the use of breath hold for free breathing in most cases $[8,9]$.

\section{Four-dimensional computed tomography (4DCT)}

Four-dimensional computed tomography (4DCT) allows to perform imaging in correlation with respiratory motion [10-12]. More precisely, images obtained in this mode are synchronized with the patient's individual respiratory phases [9]. Their election and comparison allows an accurate 3D reconstruction, based on which the precise location of the tumor and critical organs can be determined. This type of imaging requires specialized software, which allows to process patients' images, grouped by respiratory cycle phase, in the treatment planning system.

4DCT imaging can be performed either prospectively or retrospectively. The first method, a prospective study, invoIves imaging in one or more individual respiratory phases. Scans are reconstructed for selected breathing phases and external beam therapy can be performed only when the patient is currently in one of these.

In a retrospective study, all series of scans corresponding to subsequent respiratory phases are recorded. The most commonly used respiratory pattern consists of 10 phases (from maximum inspiration to maximum expiration). One or more phases can then be selected for treatment from such a 4DCT reconstruction, as is the case for prospective studies $[7,12]$. On the other hand, it is also possible to prepare the tumor contours in each reconstructed phase. The contours are then summed up and the volume defined as the internal target volume (ITV) is reconstructed. Thus, ITV contains the tumor with an anisotropic margin that takes into account the physiological movement caused by the breathing process [13, 14].

Of course, there is always a concern as to whether the set of CT scans performed in correlation with respiratory motion is representative of the patient's anatomy throughout the course of radiotherapy. In this context, it is worth presenting the literature data published by Haasbeek et al. In their analysis, a re-examination of 4DCT was performed on at least 2 treatment fractions (the average interval between the first treatment fraction and the repeated 4DCT equaled 6.6 days). Results showed no systematic changes in tumor volume or movement trajectory for almost all patients. Risks related to the insufficient coverage of the target involved an episode of atelectasis in one patient from the study group [15]. In another study, published by a German group, four series of 4DCTs performed at 10-minute intervals showed no systematic changes in the observed respiratory cycles. Increased variability was observed for tumors located in the lower lobes [8]. Further, in a study by van der Geld et al., no systematic differences were found between the tumor volumes on the basis of a comparative analysis of two successive 4DCT series. In addition, the range of planned tumor volume (PTV) mobility was less than $2 \mathrm{~mm}$ for $81 \%$ of analyzed cases. Finally, tumor coverage analyzed throughout the study group did not change significantly [16]. These studies suggest that 4DCT reproducibility is achieved by the imaging procedure in correlation with respiratory motion, as long as CT scanning commences when a regular respiratory pattern is observed after multiple respiratory cycles.

\section{CT taken with very long scan times per slice (slow CT)}

An alternative assessment of respiratory motion, also performed on the basis of computed tomography, is possible using the so-called slow CT. The additional CT scan mode extends the revolution time up to 4 seconds. There is a good reason for this: the literature indicates that this is the average length of one full respiratory cycle among the population. As a result of this scanning mode, a single set of CT scans is obtained with the potential to reconstruct all tumor positions throughout the respiratory cycle [17]. In this way, the determined volume of the tumor should correspond to the volume of ITV, and the images in the slow CT mode correspond to the average intensity projection of the images from the 4DCT reconstruction [18]. Nevertheless, the reliability of slow CT is limited to peripheral tumors [18]. When using slow CT scans in clinical practice, it is important to remember that the intensity of pixels in this imaging mode is directly proportional to the time during which the tumor remains at its extreme position. As a consequence, tumor boundaries may be blurred, which does not allow a clear assessment of the external contour of the ITV thus designated.

\section{Compensation of respiratory motion during external beam irradiation}

Technological solutions used during external beam radiation therapy treatment can be divided into two groups: 1 ) respiratory gating, 2 ) tumor tracking $[19,20]$. 


\section{Respiratory gating}

All respiratory gating solutions are associated with the interruption of ionizing radiation when the tumor is outside the therapeutic beam [21].

More precisely, chest movement and the volume of exhaled/inhaled air are correlated with the breathing phase of the patient. These parameters are controlled by a sensor system located in the therapeutic room. Data about chest position and exhaled/inhaled air is transmitted in real time to the receiving device, which then analyzes the current respiratory phase of the patient. A visual representation of the respiratory cycle is displayed on an external screen or in specially designed goggles [21]. Thanks to this solution, the patient is instructed to breathe according to a predefined pattern and consciously prolong the respiratory phase selected for planning and treatment purposes (e.g. deep inspiration breath-hold technique) [7, 22, 23].

The other respiratory gating method is directly related to the $4 D C T$ imaging technique described in the previous section. 4DCT information on the characteristics of individual respiratory motion (e.g. amplitude or period) allows to determine the time interval in which the patient will be exposed to radiation $[7,17]$. In this case, there is no need to be limited to a single respiratory phase [21]. With respect to one complete respiratory cycle, it is common to use a gate that allows $20-40 \%$ of the respiration [24]. As in the first method, the emission of ionizing radiation is controlled by a sensor system that maps the patient's breathing phase [21].

The most commonly used respiratory motion monitoring systems are:

1. Video-based technologies using an infrared tracking camera and a reflective marker, such as in Real-time Position Management systems (RPM ${ }^{\mathrm{TM}}$, Varian Medical Systems, USA).

2. Spirometry-based systems e.g. Active Breathing Coordinator ( $A B C^{T M}$, Elekta, Sweden) or SpiroDyn'RX (Dyn'R, France).

3. Laser-based optical surface scanning systems e.g. C-Rad (Sentinel, Sweden) $[3,14,25]$.

The widespread use of respiratory gating techniques in lung cancer radiotherapy has been limited thus far due to the longer irradiation time required for the gated fraction as compared to the conventional therapeutic fraction (i.e. without gating). For example, the time needed to complete the daily treatment fraction for a patient irradiated in a gate corresponding to $20 \%$ of the respiratory cycle is approximately five times longer than that for non-gated delivery.

However, it is now possible to perform irradiation on conventional linear accelerators with flattening filter-free (FFF) photon beam quality [26, 27].The dose rate for a beam generated without a flattening filter is significantly higher than that for a flattened photon beam. It can reach values of up to 2400 monitor units per minute, whereas the corre- sponding figure for the flattened beam is usually no more than 300-600 MU/min [28]. Because of the higher dose rate, less time is needed to complete the therapeutic fraction. Hence, the time would be either eight or four times shorter for an unflattened than for a flattened beam in the above-mentioned case.

Additionally, the volumetric modulated arc therapy (VMAT) technique has been implemented in clinical practice in recent years $[2,28,29]$. Its main feature is that it eliminates the time needed to set the planned static positions of the linear accelerator, which is an essential step when the treatment plan consists of many static beams [30, 31].

Both FFF beams and the VMAT technique can be accompanied by respiratory gating systems to reduce the time needed to perform the daily irradiation [32].

It is worth underlining that not all patients benefit from the use of respiratory gating techniques during their external beam treatment. Underberg et al. showed that significant benefits of the method were experienced only by $25 \%$ of patients with non-small cell lung cancer $[18,24]$. Kim et al., in turn, suggested that the solution was particularly advantageous in the treatment of small volume tumors located in the lower lobes [33].

\section{Real-time tumor tracking}

The other group of technological solutions used for respiratory motion compensation during external beam radiotherapy allows to correlate tumor position with the spatio-temporal coordinates of the treatment beam [34]. This method is known as respiratory tracking.

The ability to track and compensate tumor position changes during therapy is available in the CyberKnife system (Accuray Inc., Sunnyvale, USA) [21]. Prior to treatment, a correlation model is built between external surrogate motion and the motion of the target region. This model is then verified at regular intervals in real time (during irradiation). Tumor movement can be tracked using:

1. Externally measured surrogate data on chest wall motion. This information is collected by external infrared reflective markers placed on the patient's chest, and

2. An orthogonal X-ray imaging system integrated with the therapeutic device $[11,21]$.

The imaging system integrated with the therapeutic device consists of kilovolt sources (X-ray tubes) mounted on the ceiling of the therapeutic bunker and two X-ray detectors installed on the floor. It allows to acquire two orthogonal X-ray images with a frequency of 5 to 150 seconds $[21,22]$. With such a solution, the tumor motion analysis may be performed directly (so-called direct tracking) only if the tumor is adequately saturated (in which case it is referred to as lung tracking) or its visibility is determined by the use of markers implanted within its volume (in which case so-called fiducial tracking is used). If the tumor is situated 
near the spine, its visibility may be insufficient to allow for direct tracking. In this case, spine tracking is used as indirect tracking option [22]. It should be noted that the CyberKnife motion prediction algorithm is used to verify the model and to compensate the potential system delays resulting from the motion latency of the CyberKnife robotic arm and the latency of image acquisition.

Compared with respiratory gating, the ability to track tumor position offers potentially greater precision and faster deposition of the planned dose. Therefore, a great technological effort is being made to implement tracking techniques on conventional linear accelerators. It involves the synchronization of the tumor movement with the leaves of the multileaf collimator (MLC) [35] or with the movement of the therapeutic table [17].

\section{Summary and conclusions}

There are a number of methods used to compensate for the respiratory motion of a tumor localized within the lung. These methods can be divided into two main groups:

1. Pre-treatment, CT imaging-based methods used to precisely define the irradiated volumes.

2. Intra-fraction methods allowing the size adjustment of therapeutic fields to the shape of the tumor.

In the case of each of the described compensation techniques, the key objective is to ensure the highest possible precision during external beam radiation therapy treatment.

\section{Abbreviations}

$\mathrm{CT}$ - computed tomography

4DCT — four-dimensional computed tomography

ITV — internal target volume

VMAT - volumetric modulated arc therapy

Conflict of interest: none declared

\section{Marta Adamczyk, MSc}

Greater Poland Cancer Center in Poznań

Department of Medical Physics

ul. Garbary 15

61-866 Poznań, Poland

e-mail:marta.adamczyk@wco.pl

Received: 12 Apr 2017

Accepted: 6 Oct 2017

\section{References}

1. Dolla $Ł$, Osewski W, Hawrylewicz L et al. Wirtualna symulacja — nowy element procesu planowania radioterapii. Inżynier i Fizyk Medyczny 2014; 4: 169-174.

2. Maciejewski B. Od Roentgena (120 lat) do stereotaktycznej radiochirurgii. Nowotwory J Oncol 2015; 65: 373-382.

3. Nielsen TB, Hansen VN, Westberg J et al. A dual centre study of setup accuracy for thoracic patients based on cone-beam CT data. Radiother Oncol 2012; 102: 281-286

4. Osowiecka K, Rucińska M, Każarnowicz A et al. Przeżycia chorych na niedrobnokomórkowego raka płuca leczonych napromienianiem w latach
2003-2006 w Samodzielnym Publicznym Zakładzie Opieki Zdrowotnej Ministerstwa Spraw Wewnętrznych z Warmińsko-Mazurskim Centrum Onkologii w Olsztynie. Nowotwory J Oncol 2015; 65: 14-22.

5. Truntzer $P$, Antoni $D$, Santelmo $N$ et al. Superior sulcus non-small cell lung carcinoma: A comparison of IMRT and 3D-RT dosimetry. Rep Pract Oncol Radiother 2016; 21: 427-434.

6. Zhang Q, Xiong W, Chan MF et al. Rotation effects on the target-volume margin determination. Phys Med 2015; 31: 80-84.

7. Hawrylewicz L, Dolla $Ł$, Garbacik $S$ et al. Zastosowanie tomografu komputerowego w planowaniu rozkładu dawki w radioterapii. Inżynier i Fizyk Medyczny 2014; 3: 123-128.

8. Guckenberger M, Wilbert J, Meyer J et al. Is a single respiratory correlated 4D-CT study sufficient for evaluation of breathing motion? Int J Radiat Oncol Biol Phys 2007; 67: 1352-1359.

9. Guy CL, Weiss E, Jan N et al. Effect of atelectasis changes on tissue mass and dose during lung radiotherapy. Med Phys 2016; 43: 6109.

10. Chehade S, Palma DA. Stereotactic radiotherapy for early lung cancer: Evidence-based approach and future directions. Rep Pract Oncol Radiother 2015; 20: 403-410.

11. Cvek J, Knybel L, Molenda L et al. A single reference measurement can predict liver tumor motion during respiration. Rep Pract Oncol Radiother 2016; 21: 278-283.

12. Rodríguez-Romero $\mathrm{R}$, Castro-Tejero $\mathrm{P}$. The influence of respiratory motion on CT image volume definition. Med Phys 2014; 41: 041701.

13. Kelly $\mathrm{P}$, Balter $\mathrm{PA}$, Rebueno $\mathrm{N}$ et al. Stereotactic body radiation therapy for patients with lung cancer previously treated with thoracic radiation. Int J Radiat Oncol Biol Phys 2010; 78: 1387-1393.

14. Serpa M, Baier K, Cremers F et al. Suitability of markerless EPID tracking for tumor position verification in gated radiotherapy. Med Phys 2014; 41: 031702.

15. Haasbeek CJA, Lagerwaard FJ, Cuijpers JP et al. Is adaptive treatment planning required for stereotactic radiotherapy of stage I non-small-cell lung cancer? Int J Radiat Oncol Biol Phys 2007; 67: 1370-1374.

16. van der Geld YG, Lagerwaard FJ, van Sörnsen de Koste JR et al. Reproducibility of target volumes generated using uncoached 4-dimensional CT scans for peripheral lung cancer. Radiat Oncol 2006; 1: 43.

17. Verellen $D$, De Ridder $M$, Linthout $N$ et al. Innovations in image-guided radiotherapy. Nat Rev Cancer 2007; 7: 949-960.

18. Underberg RW, Lagerwaard FJ, Slotman BJ et al. Use of maximum intensity projections (MIP) for target volume generation in 4DCT scans for lung cancer. Int J Radiat Oncol Biol Phys 2005; 63: 253-260.

19. Maciejczyk A, Skrzypczyńska I, Janiszewska M. Lung cancer. Radiotherapy in lung cancer: Actual methods and future trends. Rep Pract Oncol Radiother 2014; 19: 353-360.

20. Rubio $C$, Morera $R$, Hernando $O$ et al. Extracranial stereotactic body radiotherapy. Review of main SBRT features and indications in primary tumors. Rep Pract Oncol Radiother 2013; 18: 387-396.

21. Ślosarek K. Akceleratory terapeutyczne stosowane w radioterapii. Inżynier i Fizyk Medyczny 2014; 2: 103-109.

22. Adamczyk M. Aspekty fizyczne leczenia stereotaktycznego w świetle doniesień zaprezentowanych podczas konferencji ASTRO 56 w San Francisco. Zeszyty Naukowe WCO, Letters in Oncology Science 2015; 12: 14-18.

23. Garibaldi C, Catalano G, Baroni G et al. Deep inspiration breath-hold technique guided by an opto-electronic system for extracranial stereotactic treatments. J Appl Clin Med Phys 2013; 14: 4087.

24. Underberg RW, Lagerwaard FJ, Slotman BJ et al. Benefit of respiration-gated stereotactic radiotherapy for stage I lung cancer: An analysis of 4DCT datasets. Int J Radiat Oncol Biol Phys 2005; 62: 554-560.

25. Dąbrowski A. Laserowe systemy Sentinel do weryfikacji geometrii pacjenta w radioterapii. Inżynier i Fizyk Medyczny 2013; 2: 113-114.

26. Hrbacek J, Lang S, Graydon SN et al. Dosimetric comparison of flattened and unflattened beams for stereotactic ablative radiotherapy of stage I non-small cell lung cancer. Med Phys 2014; 41: 031709.

27. Peguret N, Dahele M, Cuijpers JP et al. Frameless high dose rate stereotactic lung radiotherapy: Intrafraction tumor position and delivery time. Radiother Oncol 2013; 107: 419-422.

28. Radwan M, Grządziel A, Hawrylewicz L et al. The influence of photon energy on dose distribution for IMRT and VMAT plans. Nowotwory $\mathrm{J}$ Oncol 2014; 64: 230-236.

29. Thiyagarajan R, Nambiraj A, Sinha SN et al. Analyzing the performance of ArcCHECK diode array detector for VMAT plan. Rep Pract Oncol Radiother 2016; 21: 50-56.

30. Cai J, Malhotra HK, Orton CG. Point/Counterpoint. A 3D-conformal technique is better than IMRT or VMAT for lung SBRT. Med Phys 2014; 41: 040601. 
31. Rao M, Ye J, Spiegel J et al. Interplay effect during lung SBRT with VMAT delivered by flattening filter-free beams. Int J Radiat Oncol Biol Phys 2014; 90: S192.

32. Chow JC, Owrangi AM. A surface energy spectral study on the bone heterogeneity and beam obliquity using the flattened and unflattened photon beams. Rep Pract Oncol Radiother 2016; 21: 63-70.

33. Kim J, Zhao B, Ajlouni $M$ et al. Are clinically relevant dosimetric endpoints significantly better with gating of lung SBRT vs. ITV-based treatment? Results of a large cohort investigation analyzing predictive dosimetric indicators as a function of tumor volume and motion amplitude. Med Phys 2015; 42: 3204.

34. Janiga P. Stereotaktyczna radioterapia niedrobnokomórkowego raka płuca we wczesnym stadium zaawansowania - czy napromienianie może zastapić chirurgię? Zeszyty Naukowe WCO, Letters in Oncology Science 2014; 11: 27-32

35. GeY, O'Brien RT, Shieh CC et al. Toward the development of intrafraction tumor deformation tracking using a dynamic multi-leaf collimator. Med Phys 2014; 41: 061703. 